\title{
As an unusual traumatic presentation, acetabular fracture and concomitant ipsilateral intertrochanteric femur fracture: a retrospective case series of 18 patients
}

\author{
Bo Liư ${ }^{\dagger}$ Wenhui Ma`, Sikai Liu, Xiao Chen, Mengnan Li, Jia Huo, Huijie Li and Yongtai Hanº
}

\begin{abstract}
Background: Acetabular fracture and concomitant ipsilateral intertrochanteric femur fracture has been suggested as an unusual traumatic presentation and rarely reported in the literature. The aims of this study were (1) to identify the etiological characteristics, (2) to summarize the treatment strategy, and (3) to present the mid- to long-term results of patients with this rare traumatic presentation.

Methods: In this retrospective study, 18 patients ( 15 males, 3 females; mean age $=42.77 \pm 17.74$ years, range $=16$ to 87 years) who were diagnosed and treated for simultaneous acetabular fracture and ipsilateral intertrochanteric fracture were included. Injury mechanisms, fracture classifications, and treatment strategies were noted. To assess functional status, the Harris score was used. To evaluate pain intensity, visual analogous scale (VAS) was used. The reduction quality of acetabular fractures was examined as per Matta's standard. Postoperative complications were also recorded.

Results: The mean follow-up was $10.04 \pm 3.38$ (range $=6.2$ to 16 years). The most common injury mechanism was traffic accident, followed by falling from a tall height. As per the Evans classification, intertrochanteric fractures were defined as type 3 in 13 patients, type 2 in one patient, and type 4 in 4 patients. In acetabular fracture site, the most common fractures were posterior wall fractures, followed by anterior column fractures. All patients received internal fixation for their intertrochanteric fractures. Ten out of 18 patients also received internal fixation for their acetabular fracture. However, for the remaining patients, acetabular fractures were treated conservatively or with fracture fragment resection. Bony healing was achieved in all but one patient who died postoperatively. Twelve patients achieved excellent and good results (Harris score $\geq 80$ points) whereas five patients achieved fair and poor results (Harris score < 80 points). The proportion of patients who achieved an excellent-good Harris score was 70.6\%. Dislocation of the hip was found to be an independent risk factor ( $\mathrm{HR}=9.194,95 \% \mathrm{Cl}=1.024-82.515)$ for the poor patient outcome.

(Continued on next page)
\end{abstract}

\footnotetext{
* Correspondence: yongtaihan@foxmail.com

${ }^{\dagger}$ Bo Liu and Wenhui Ma contributed equally to this work.

Department of Osteonecrosis and Hip Surgery, The Third Hospital of Hebei

Medical University, No.139 Ziqiang Road, Shijiazhuang, Hebei, People's

Republic of China
}

C C The Author(s). 2020 Open Access This article is licensed under a Creative Commons Attribution 4.0 International License, which permits use, sharing, adaptation, distribution and reproduction in any medium or format, as long as you give appropriate credit to the original author(s) and the source, provide a link to the Creative Commons licence, and indicate if changes were made. The images or other third party material in this article are included in the article's Creative Commons licence, unless indicated otherwise in a credit line to the material. If material is not included in the article's Creative Commons licence and your intended use is not permitted by statutory regulation or exceeds the permitted use, you will need to obtain permission directly from the copyright holder. To view a copy of this licence, visit http://creativecommons.org/licenses/by/4.0/ The Creative Commons Public Domain Dedication waiver (http://creativecommons.org/publicdomain/zero/1.0/) applies to the data made available in this article, unless otherwise stated in a credit line to the data. 


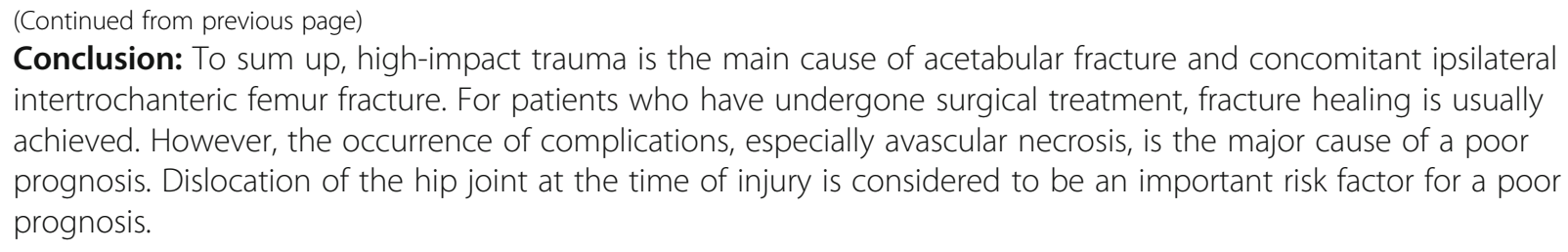

Keywords: Fracture, Dislocation, Acetabulum, Intertrochanteric fracture

\section{Background}

Fractures involving both the acetabulum and femoral trochanter have rarely been reported. The aetiology, treatment methods, and prognosis of this severe injury and the characteristics of patients with this injury remain unknown. Therefore, an investigation with a relatively large sample size needs to be conducted in patients with acetabular fractures and ipsilateral intertrochanteric fractures to help orthopaedic and traumatic surgeons manage such patients.

Generally, an acetabular fracture (especially a posterior wall fracture, the most common type of acetabular fracture) is usually caused by high-impact trauma, such as a car accident or a fall from a tall height $[1,2]$. A so-called dashboard injury includes a fracture in the posterior wall of the acetabulum with or without anatomical insult to the proximal femur [3]. However, to date, only a few case reports of acetabular fractures combined with ipsilateral intertrochanteric fractures have been reported [4-6]. Browne et al reported three patients with this kind of injury [6]. Two of the injuries were caused by traffic accidents, and the other patient was injured via a fall from height. All three patients underwent open reduction and internal fixation (ORIF). However, the prognosis was not mentioned. Kuhn et al and Barrett et al separately reported similar cases $[4,5]$. Both of the patients were injured in traffic accidents and were also treated with ORIF. However, owing to the limited sample size, the results might only reflect one or several aspects of the fracture characteristics. As already described by Mediouni et al., the goal of modern orthopaedic research is to fill the gap between basic sciences and clinical sciences, as well as contribute to translational orthopaedics [7-9]. To that end, we examined a case series of 18 patients with acetabular fractures combined with ipsilateral intertrochanteric fractures.

The aims of this study were (1) to identify the etiological characteristics, (2) to summarize the treatment strategy, and (3) to present the mid- to long-term results of patients with this rare traumatic presentation.

\section{Patients and methods}

This study was approved by the Institutional Review Board of the Third Hospital of Hebei Medical University and was conducted in accordance with the Declaration of Helsinki. As this was a retrospective study and all patient information was deidentified before analysis, informed consent was only required for the patients whose radiological images were selected for publication. We retrospectively reviewed a total of 18 patients from 2003 to 2013. The inclusion criteria were patients who were treated in our hospital for combined ipsilateral acetabular fractures and intertrochanteric fractures. Patients were excluded if they had a history of old fractures involving the proximal femur or acetabulum, hip joint infections, or pathological fractures owing to a malignant disease. The general information, aetiology, and fracture classifications of the cases were identified based on either the patient's radiological data or medical records. These data were collected and analysed by three authors (XC, ML, and JH). Evans' classification system was used to evaluate the intertrochanteric fractures [3]. Moreover, the acetabular fracture sites were identified. The Arbeitsgemeinschaft für Osteosythesefragen/Orthopaedic Trauma Association (AO/OTA) classification system was also used to determine the fracture type of both the acetabular and femoral fractures [10].

\section{Treatments}

All patients underwent surgical treatment for their fractures. The surgeries were performed by the same group of surgeons ( $\mathrm{YH}, \mathrm{BL}, \mathrm{WM}, \mathrm{SL}$, and $\mathrm{HL})$. All surgical treatments were performed electively when the patient's haemodynamic status was stable. No emergency surgical treatments were performed. For some patients who had hip dislocation, reduction of the dislocated joint was performed at the same time as surgical treatment of the fracture. No emergency closed reductions were performed.

There were generally two types of surgical treatments: surgical treatment for acetabular fractures and surgical treatment for intertrochanteric fractures. In this study, the indications for surgical treatment for acetabular fractures were the presence of a large posterior wall fracture (affecting more than $30 \%$ of the area of the posterior wall), displacement exceeding $2 \mathrm{~mm}$, an anterior or posterior column fracture, joint instability, and intraarticular free body formation. In other situations, for instance, an 
isolated posterior wall fracture (62-A1) without displacement exceeding $2 \mathrm{~mm}$, conservative treatment might be sufficient for acetabular fractures. The most common surgical procedure for acetabular fractures is open reduction and internal fixation (ORIF). However, in some circumstances, the fracture fragment is too small to fix, and resection of the fragment is performed. In this study, all patients underwent surgical treatment (internal fixation) for the intertrochanteric fracture. If the acetabular fracture was surgically treated, the intertrochanteric fracture was reduced and fixed simultaneously with the same incision (or same operation) as was the acetabular fracture. If the acetabular fracture was treated conservatively, the intertrochanteric fracture was fixed with dynamic hip screws through the lateral approach or fixed with an intramedullary nail using a minimally invasive technique (closed reduction and internal fixation, CRIF).

Postoperatively, all patients received anti-thrombosis therapy. Non-weight-bearing movement of the hip joint was encouraged as soon as the pain could be tolerated. For the first 4 weeks, the patients were advised to avoid weight bearing on the affected limb. The patients attended 4 follow-ups (at 4 weeks, 12 weeks, 6 months, and 1 year) during the first year postoperatively. We used X-ray imaging to evaluate the bone healing conditions, and the X-ray scans were taken at the patients' follow-ups. When callus formation was detected, the patient was allowed to perform partial weight-bearing (standing or walking with a cane or a walker). Full weight-bearing was allowed when the fracture was considered to exhibit a union.

\section{Outcome evaluation}

The Harris score was used to evaluate the functional outcome [11]. The Harris scoring system consists of three parts: a pain assessment (44 points in total), functional assessment (51 points in total), and range of motion assessment (5 points in total). It has the advantages of high accuracy and good repeatability [11]. Pain was evaluated by using a $100-\mathrm{mm}$ visual analogue scale (VAS) [12, 13]. Harris scores and VAS scores of patients were evaluated by three authors $(\mathrm{XC}, \mathrm{ML}$, and $\mathrm{JH})$. The degree of pain was graded as follows: $1-3$ points for mild pain, 4-6 points for moderate pain, and 7-10 points for severe pain. The reduction quality of the acetabular fracture was also investigated. The reduction quality was evaluated and analysed according to Matta's standard [14], which was as follows: steps $0-2 \mathrm{~mm}$ indicated excellent-good reduction, steps $2-3 \mathrm{~mm}$ indicated fair reduction, and steps $>3 \mathrm{~mm}$ indicated poor reduction. The duration of bone healing and incidence of complications were also investigated [11]. If conversion to total hip arthroplasty (THA) was performed in a patient, the time to THA and the Harris score before THA were also recorded. A patient was considered to have poor outcomes if the Harris score was less than 80 points or if the patient underwent conversion to THA.

\section{Statistical analysis}

Statistical analyses were performed using the statistical software SPSS, version 19.0 for Windows (IBM, Armonk, New York). The continuous variables were expressed as the mean $\pm \mathrm{SD}$ (range), and the categorical variables were expressed as frequencies. A paired $t$ test was used to compare the Harris score between the affected limb and the opposite limb. Cox regression analyses were used to assess the association between potential risk factors and poor outcomes in patients. Owing to the limited sample size, we first built univariable Cox regression models to find the potential risk factors. Then, a multivariable Cox regression model was built to find the independent risk factors for poor outcomes. A $p$ value less than 0.05 was considered significant.

\section{Results \\ General information}

A total of 18 patients were initially included in this study. The mean age of the patients was $42.77 \pm 17.74$ years (range from 16 years to 87 years). There were 15 males and 3 females. In this study, injuries occurred most commonly via traffic accidents. Falling from a tall height was the second most common cause of injury, followed by a crushing event. Only one elderly ( 87 years) female patient was injured by slipping and falling on the ground. Six patients had posterior dislocation of the hip joint. All patients received surgical treatment, and the mean time to surgery was $8.72 \pm 5.37$ days (range from 3 days to 23 days). In terms of comorbidities, one patient had acute respiratory distress syndrome (oxygenation index $=130 \mathrm{mmHg}$ ) and was treated with mechanical ventilation in the intensive care unit. Traumatic shock was identified in two patients, who were treated with fluid resuscitation (including transfusion) and vasoactive agents. One patient had a history of pneumonia. Multiple rib fractures and pneumohemothorax were identified in one patient, who was treated conservatively. Seven patients had other fractures; there was a pubic fracture in five patients (treated conservatively), fractures of the ulna and radius in one patient (treated by open reduction and internal fixation), and a clavicle fracture in one patient (treated conservatively). Except for the patient who had a history of pneumonia, the comorbidities of all other patients were cured without significant aftereffects. The follow-up time was 6.2 to 16 years. Details of the patients' general characteristics are shown in Table 1. 
Table 1 General characteristics of the patients and fracture classifications

\begin{tabular}{|c|c|c|c|c|c|c|c|c|c|}
\hline Case & Age (years) & Sex & Side & Aetiology & $\begin{array}{l}\text { Dislocation } \\
\text { of hip }\end{array}$ & $\begin{array}{l}\text { Time to } \\
\text { surgery } \\
\text { (days) }\end{array}$ & $\begin{array}{l}\text { Evans classification } \\
\text { for intertrochanteric } \\
\text { fracture (AO/OTA } \\
\text { classification) }\end{array}$ & $\begin{array}{l}\text { Classification for } \\
\text { acetabular fracture } \\
\text { (AO/OTA classification) }\end{array}$ & $\begin{array}{l}\text { Follow-up } \\
\text { time (years) }\end{array}$ \\
\hline 1 & 49 & Male & Right & Crushing injury & No & 8 & Type IV (31-A2) & Posterior Wall (62-A1) & 16.0 \\
\hline 2 & 46 & Male & Left & Crushing injury & No & 14 & Type III (31-A2) & $\begin{array}{l}\text { Transverse \& Posterior } \\
\text { Wall (62-B1) }\end{array}$ & 15.7 \\
\hline 3 & 46 & Male & Right & $\begin{array}{l}\text { Fall from a tall } \\
\text { height }\end{array}$ & No & 8 & Type III (31-A2) & Anterior Column (62-A3) & 15.4 \\
\hline 4 & 31 & Female & Right & Crushing injury & Yes & 3 & Type III (31-A2) & Anterior Column (62-A3) & 13.6 \\
\hline 5 & 26 & Male & Left & Traffic accident & No & 5 & Type III (31-A1) & Posterior Wall (62-A1) & 12.0 \\
\hline 6 & 42 & Male & Right & $\begin{array}{l}\text { Fall from a tall } \\
\text { height }\end{array}$ & No & 4 & Type III (31-A2) & Posterior Wall (62-A1) & 11.4 \\
\hline 7 & 25 & Female & Left & Traffic accident & Yes & 12 & Type III (31-A1) & Posterior Wall (62-A1) & 10.0 \\
\hline 8 & 69 & Male & Left & Traffic accident & No & 6 & Type III (31-A1) & Posterior Wall (62-A1) & 9.5 \\
\hline 9 & 87 & Female & Left & Slip, trip, or fall & No & 15 & Type III (31-A2) & Posterior Wall (62-A1) & - \\
\hline 10 & 47 & Male & Right & Traffic accident & No & 5 & Type IV (31-A2) & Posterior Wall (62-A1) & 9.3 \\
\hline 11 & 22 & Male & Right & Traffic accident & Yes & 5 & Type III (31-A2) & $\begin{array}{l}\text { Transverse \& Posterior } \\
\text { Wall }(62-\mathrm{B} 1)\end{array}$ & 7.8 \\
\hline 12 & 47 & Male & Left & Traffic accident & Yes & 8 & Type IV (31-A2) & Posterior Wall (62-A1) & 8.0 \\
\hline 13 & 42 & Male & Left & Traffic accident & No & 6 & Type II (31-A1) & Posterior Wall (62-A1) & 7.7 \\
\hline 14 & 39 & Male & Right & Traffic accident & Yes & 4 & Type III (31-A1) & Posterior Wall (62-A1) & 7.8 \\
\hline 15 & 16 & Male & Left & Traffic accident & No & 4 & Type IV (31-A2) & Posterior Column (62-A2) & 7.2 \\
\hline 16 & 43 & Male & Right & Traffic accident & No & 15 & Type III (31-A1) & Posterior Wall (62-A1) & 6.6 \\
\hline 17 & 28 & Male & Right & $\begin{array}{l}\text { Fall from a tall } \\
\text { height }\end{array}$ & Yes & 12 & Type III (31-A2) & Posterior Wall (62-A1) & 6.4 \\
\hline 18 & 65 & Male & Right & $\begin{array}{l}\text { Fall from a tall } \\
\text { height }\end{array}$ & No & 23 & Type III (31-A1) & Anterior Column (62-A3) & 6.2 \\
\hline
\end{tabular}

Note: The patient in case 9 died because of pulmonary infection after the operation

\section{Treatments}

For acetabular fractures, 6/18 patients underwent conservative treatment, $2 / 18$ patients underwent resection of the fracture fragments, and 10/18 patients underwent open reduction and internal fixation (ORIF). Nine of 12 patients underwent ORIF or resection via the KocherLangenbeck approach. In addition, the ilioinguinal approach, Watson-Jones approach and Smith-Peterson approach were used for the other three patients (Table 2). According to Matta's standard, excellent or good reduction was achieved in 14 patients, and fair reduction was achieved in 3 patients [14]. There was one patient with poor fracture reduction. In terms of treatment for the intertrochanteric fractures, twelve of the eighteen intertrochanteric fractures were reduced and fixed via the same incision (or same operation) as that used for the acetabular fracture, 2/18 were reduced and fixed via the lateral approach, and 4/18 were reduced and fixed via the minimally invasive approach (closed reduction and internal fixation). According to the type of internal fixation, 5/18 intertrochanteric fractures were treated by a dynamic hip screw (DHS), 9/18 intertrochanteric fractures were treated by an intramedullary nail, and 4/ 18 intertrochanteric fractures were treated by a plate and screws (Table 2).

\section{Prognosis}

One elderly (87 years) female patient had a pulmonary disease and died at 24 days postoperatively because of an uncontrollable pulmonary infection (therefore, we excluded this patient from our study cohort when analysing the prognosis and its influencing factors). In the other patients, all the fractures demonstrated bony healing. In 13/17 patients, fracture union was identified at 12 weeks postoperatively. In the other $4 / 17$ patients, fracture union was identified at 24 weeks postoperatively.

The average visual analogue scale score and Harris score at the final follow-up (or before arthroplasty in the patients who underwent conversion to total hip arthroplasty) were $1.71 \pm 2.08$ points (range from 0 points to 6 points) and $84.12 \pm 11.72$ points (range from 55 points to 96 points), respectively. The average Harris score was significantly lower for the affected limb than for the 
Table 2 Treatment methods performed among the patients

\begin{tabular}{|c|c|c|c|c|c|c|}
\hline \multirow[t]{2}{*}{ Case } & \multicolumn{3}{|c|}{ Acetabular fracture } & \multicolumn{3}{|c|}{ Intertrochanteric fracture } \\
\hline & Treatment & Approach & Internal fixation & Treatment & Approach & Internal fixation \\
\hline 1 & ORIF & Kocher-Langenbeck & Screws & ORIF & Same incision for acetabular fracture & DHS \\
\hline 2 & ORIF & Kocher-Langenbeck & Plate with screws & ORIF & Same incision for acetabular fracture & DHS \\
\hline 3 & Conservative & - & - & ORIF & Lateral approach & DHS \\
\hline 4 & ORIF & Ilioinguinal approach & Plate with screws & ORIF & Same incision for acetabular fracture & DHS \\
\hline 5 & Conservative & - & - & ORIF & Lateral approach & Intramedullary nail \\
\hline 6 & ORIF & Watson-Jones & Plate with screws & ORIF & Same incision for acetabular fracture & DHS \\
\hline 7 & ORIF & Kocher-Langenbeck & Screws & ORIF & Same incision for acetabular fracture & Plate with screws \\
\hline 8 & Conservative & - & - & CRIF & - & Intramedullary nail \\
\hline 9 & Conservative & - & - & CRIF & - & Intramedullary nail \\
\hline 10 & ORIF & Kocher-Langenbeck & Plate with screws & ORIF & Same incision for acetabular fracture & Intramedullary nail \\
\hline 11 & ORIF & Kocher-Langenbeck & Plate with screws & ORIF & Same incision for acetabular fracture & Plate with screws \\
\hline 12 & Resection & Kocher-Langenbeck & - & ORIF & Same incision for acetabular fracture & Intramedullary nail \\
\hline 13 & Conservative & - & - & CRIF & - & Intramedullary nail \\
\hline 14 & ORIF & Kocher-Langenbeck & Plate with screws & ORIF & Same incision for acetabular fracture & Plate with screws \\
\hline 15 & ORIF & Kocher-Langenbeck & Plate with screws & ORIF & Same incision for acetabular fracture & Intramedullary nail \\
\hline 16 & Resection & Smith-Peterson & - & ORIF & Same incision for acetabular fracture & Intramedullary nail \\
\hline 17 & ORIF & Kocher-Langenbeck & Screws & ORIF & Same incision for acetabular fracture & Plate with screws \\
\hline 18 & Conservative & - & - & CRIF & - & Intramedullary nail \\
\hline
\end{tabular}

ORIF open reduction and internal fixation, CRIF closed reduction and internal fixation, DHS dynamic hip screw

opposite $\operatorname{limb}(84.12 \pm 11.72$ vs. $99.18 \pm 1.07, t=-$ 5.196, $p<0.001)$. There were 12 patients with excellent or good results (Harris score $\geq 80$ points) and 5 patients with fair or poor results (Harris score $<80$ points). The proportion of patients with an excellent or good Harris score was $70.6 \%$. Three patients underwent conversion to total hip arthroplasty (THA). The time from the initial treatment to THA was 1.8 years, 2.2 years, and 2.5 years for these three patients. The prognoses of the patients are shown in Table 3.

Three kinds of complications were commonly identified in the patients with acetabular fractures and ipsilateral intertrochanteric fractures. Heterotopic ossification (HO) was identified in 6/17 patients. Two cases were classified as Brooker grade 3, and four cases were classified as Brooker grades $1-2$. Ten of 17 patients were found to have signs of posttraumatic arthritis. There was one patient with arthritis of Kellgren-Lawrence grade 3 and 9 patients with arthritis of Kellgren-Lawrence grades 1-2. Avascular necrosis was identified in four patients. Three of these patients underwent conversion to THA (Table 3).

Cox regression models were built to identify the potential risk factors for poor patient outcomes. The univariate Cox regression models revealed that only hip dislocation was a potential risk factor (Table 4). Then, a multivariate Cox regression model was built to identify the independent risk factors. Stepwise regression revealed that only dislocation of the hip was an independent risk factor $(\mathrm{HR}=9.194,95 \% \mathrm{CI}=1.024-$ 82.515 ) for poor outcomes in the patients (Table 5). The survivorship curve is shown in Fig. 1.

\section{Discussion}

\section{General characteristics}

Fractures involving both the acetabulum and ipsilateral femoral trochanter have rarely been reported [15]. Generally, the patients in this study had several of the same characteristics. First, almost all the patients were victims of high-impact trauma (e.g., a traffic accident or a fall from a tall height). Comorbidities such as dislocation of the hip joint, traumatic shock, and fractures at other sites were commonly identified in these patients. Second, for the patients with hip joint dislocation, closed reduction was not successful. The integrity of the femur had been compromised. Third, surgical interventions were necessary for all intertrochanteric fractures. However, for acetabular fractures, conservative treatment was performed for certain cases. Finally, most patients demonstrated acceptable hip joint function (Harris score $>80$ points) after undergoing open reduction and internal fixation treatment. However, some patients, especially those who had concomitant hip joint dislocation, had a poor prognosis.

\section{Treatments}

Because they result from high-impact, intra-articular injuries, acetabular fractures with ipsilateral 
Table 3 Prognosis and complications of the patients at the final follow-up

\begin{tabular}{|c|c|c|c|c|c|c|c|c|c|}
\hline Case & Reduction quality ${ }^{\mathbf{b}}$ & $\begin{array}{l}\text { Bone healing } \\
\text { time (weeks) }\end{array}$ & $\begin{array}{l}\text { Harris } \\
\text { score }\end{array}$ & VAS score & $\begin{array}{l}\text { Heterotopic } \\
\text { ossification } \\
\text { (Brooker } \\
\text { grade) } \\
\end{array}$ & $\begin{array}{l}\text { Posttraumatic } \\
\text { arthritis (Kellgren- } \\
\text { Lawrence grade) }\end{array}$ & $\begin{array}{l}\text { Avascular } \\
\text { necrosis of } \\
\text { femoral head }\end{array}$ & $\begin{array}{l}\text { Converted } \\
\text { to THA }\end{array}$ & Time to THA \\
\hline 1 & Excellent-good & 12 & 92 & 0 & - & 0 & No & No & - \\
\hline 2 & Fair & 12 & 85 & 1 & - & 1 & No & No & - \\
\hline 3 & Excellent-good & 12 & 89 & 1 & - & 1 & No & No & - \\
\hline 4 & Excellent-good & 24 & 91 & 0 & - & 0 & No & No & - \\
\hline 5 & Excellent-good & 24 & 88 & 0 & - & 0 & No & No & - \\
\hline 6 & Excellent-good & 12 & 96 & 0 & 3 & 0 & No & No & - \\
\hline 7 & Poor & 24 & 79 & 4 & - & 3 & No & No & - \\
\hline 8 & Excellent-good & 12 & 93 & 1 & - & 0 & No & No & - \\
\hline 9 & - & - & - & - & - & - & - & - & - \\
\hline 10 & Excellent-good & 12 & 93 & 0 & 1 & 1 & No & No & - \\
\hline $11^{\mathrm{a}}$ & Fair & 12 & 55 & 5 & - & 1 & Yes & Yes & 2.2 \\
\hline $12^{\mathrm{a}}$ & Excellent-good & 12 & 67 & 6 & 1 & 2 & Yes & Yes & 1.8 \\
\hline 13 & Excellent-good & 24 & 91 & 0 & - & 0 & No & No & - \\
\hline 14 & Excellent-good & 12 & 84 & 1 & - & 2 & No & No & - \\
\hline 15 & Fair & 12 & 96 & 0 & 1 & 0 & No & No & - \\
\hline $16^{\mathrm{a}}$ & Excellent-good & 12 & 66 & 5 & 3 & 1 & Yes & Yes & 2.5 \\
\hline 17 & Excellent-good & 12 & 77 & 3 & 2 & 1 & Yes & No & - \\
\hline 18 & Excellent-good & 12 & 88 & 2 & - & 1 & No & No & - \\
\hline
\end{tabular}

Note: The patient in case 9 died because of pulmonary infection after the operation VAS visual analogue scale, THA total hip arthroplasty

aLast follow-up before total hip arthroplasty

${ }^{\mathrm{b}}$ Matta's standard for acetabular fractures

intertrochanteric fractures are innately difficult for surgeons to manage $[4,6,16,17]$. In this study, instead of an emergency surgery, all patients underwent an operation several days after the injury, when he or she was haemodynamically stable and well prepared for surgery. In the studies by Kuhn et al. and Barrett et al., the periods from the injury to surgery were 4 days and 5 days, respectively $[4,5]$. As in our study, this delay was introduced to wait for the patient's physiologic condition to stabilize.

For acetabular fractures, surgical treatment is not always necessary because some fractures are considered stable without displacement, and the fracture has little influence on the function of the hip joint during weightbearing [18-21]. The type of treatment selected is also influenced by the surgeon's experience and preference. In 1980, Browne et al. reported three similar patients. In all of them, the acetabular fractures were treated conservatively. However, in two recent reports, all the acetabular fractures were treated surgically with open reduction and internal fixation. In this study, when a fracture was considered unstable with displacement exceeding $2 \mathrm{~mm}$, surgical treatment was performed to achieve anatomical reduction and prevent the development of posttraumatic arthritis [22-24]. The results showed that most patients achieved excellent or good reduction of the acetabular fractures. This might be the reason why the incidence of post-traumatic arthritis was relatively low in our study. Reconstruction plates and screws were the most commonly used internal fixation tools for acetabular fractures.

The treatment principle for an intertrochanteric fracture combined with an acetabular fracture is similar to that of an isolated intertrochanteric fracture. Intertrochanteric fractures are generally considered unstable; thus, surgical treatment is performed in all patients $[3,25]$. If a patient receives surgical treatment for an acetabular fracture, the intertrochanteric fracture can be treated by the same incision (or with an extension). Otherwise, the intertrochanteric fracture can be treated with a minimally invasive surgical procedure (closed reduction and internal fixation). In the past, dynamic hip screws were commonly used for intertrochanteric fracture fixation, and more recently, intramedullary nails and plates (with screws) have been commonly used. By the surgical or conservative treatment described above, both acetabular and intertrochanteric fractures achieved bony healing in all patients. 
Table 4 Univariate Cox regression models for the potential risk factors for poor outcomes in the patients

\begin{tabular}{|c|c|c|c|c|}
\hline Risk factors & & HR & $95 \% \mathrm{Cl}$ & $p$ \\
\hline Age (years) & & 0.959 & $0.890-1.033$ & 0.269 \\
\hline \multirow[t]{2}{*}{ Sex } & Male (Ref.) & & & \\
\hline & Female & 1.293 & $0.139-11.994$ & 0.821 \\
\hline \multirow[t]{2}{*}{ Side } & Left (Ref.) & & & \\
\hline & Right & 1.066 & $0.178-6.399$ & 0.994 \\
\hline \multirow[t]{2}{*}{ Aetiology } & Traffic accident (Ref.) & & & \\
\hline & Other & 0.234 & $0.025-2.201$ & 0.204 \\
\hline \multirow[t]{2}{*}{ Dislocation of the hip } & No (Ref.) & & & \\
\hline & Yes & 9.194 & $1.024-2.515$ & 0.048 \\
\hline Time to surgery (days) & & 1.091 & $0.936-1.270$ & 0.266 \\
\hline \multirow[t]{2}{*}{ Evans classification for intertrochanteric fracture } & 2 or 3(Ref.) & & & \\
\hline & 4 & 1.005 & $0.111-9.057$ & 0.997 \\
\hline \multirow[t]{2}{*}{ Acetabular fracture site } & Posterior wall (Ref.) & & & \\
\hline & Other & 0.443 & $0.049-3.987$ & 0.468 \\
\hline \multirow[t]{2}{*}{ Treatment for the acetabular fracture } & Conservative or Resection (Ref.) & & & \\
\hline & ORIF & 0.828 & $0.137-5.005$ & 0.837 \\
\hline \multirow[t]{2}{*}{ Reduction quality of the acetabular fracture } & Excellent-good (Ref.) & & & \\
\hline & Fair-poor & 2.002 & $0.333-12.043$ & 0.448 \\
\hline
\end{tabular}

Note: For patients who underwent conversion to total hip arthroplasty, the survival time is the period between the time of fracture occurrence and the time of total hip arthroplasty. Survival events were defined in patients who did not undergo total hip arthroplasty and had a Harris score higher than 80 points at the last follow-up

$H R$ hazard ratio, $\mathrm{Cl}$ confidence interval, ORIF open reduction and internal fixation

\section{Prognosis}

In this study, the majority of patients achieved excellent or good hip function (Harris score $\geq 80$ points). Unfortunately, there were still 5 patients with poor outcomes. From the results, we found that the onset of complications, especially avascular necrosis, is the main cause of poor clinical outcomes.

It is well known that an isolated acetabular fracture can cause avascular necrosis of the femoral head, but the incidence rate is relatively low $[26,27]$. In a recent study, the incidence of avascular necrosis was $5.6 \%$ after a traumatic acetabular fracture [11] (Figs. 2 and 3). However, in this study, the incidence of avascular necrosis was extraordinarily high. Furthermore, in our Cox regression models, dislocation of the hip joint was identified as the sole

Table 5 Multivariate Cox regression models for the potential risk factors for poor outcomes in the patients (only the variables in the equation are shown in the table)

\begin{tabular}{lllll}
\hline Risk factors & & HR & $\mathbf{9 5 \% ~ C l}$ & $\boldsymbol{p}$ \\
\hline Dislocation of hip & No (Ref.) & & & \\
& Yes & 9.194 & $1.024-82.515$ & 0.048
\end{tabular}

Note: Covariates including age, aetiology, dislocation of hip, and time to surgery were initially entered into the equation. By stepwise regression, only dislocation of the hip was a certain risk factor

$H R$ hazard ratio, $\mathrm{Cl}$ confidence interval independent risk factor for poor outcomes. When the fractures were combined with a dislocated hip joint, the patient was not treated with emergency closed reduction because the continuity of the femur was damaged, thus making closed reduction quite difficult to perform. On the basis of the results of some similar studies and our results [4-6], we suspect that when the hip joint is not reduced, the blood supply of the femoral head might be affected, causing avascular necrosis and leading to poor clinical outcomes. Although some recent studies have shown that early reduction of the dislocated hip joint does not have a large favourable impact in terms of avascular necrosis $[1,15,28]$, the results of our study showed that delayed reduction might be a cause of poor outcomes that cannot be dismissed. Hence, rapid reduction of the hip joint should be considered in the future to prevent avascular necrosis.

In addition, we found that most cases of avascular necrosis are identified within 3 years after the injury.

\section{Limitations}

This study has several limitations. First, this is a retrospective study with a small sample size, so some important information and potential risk factors may not have been accounted for. Second, with severe injuries such as the fractures examined herein, patients often have 


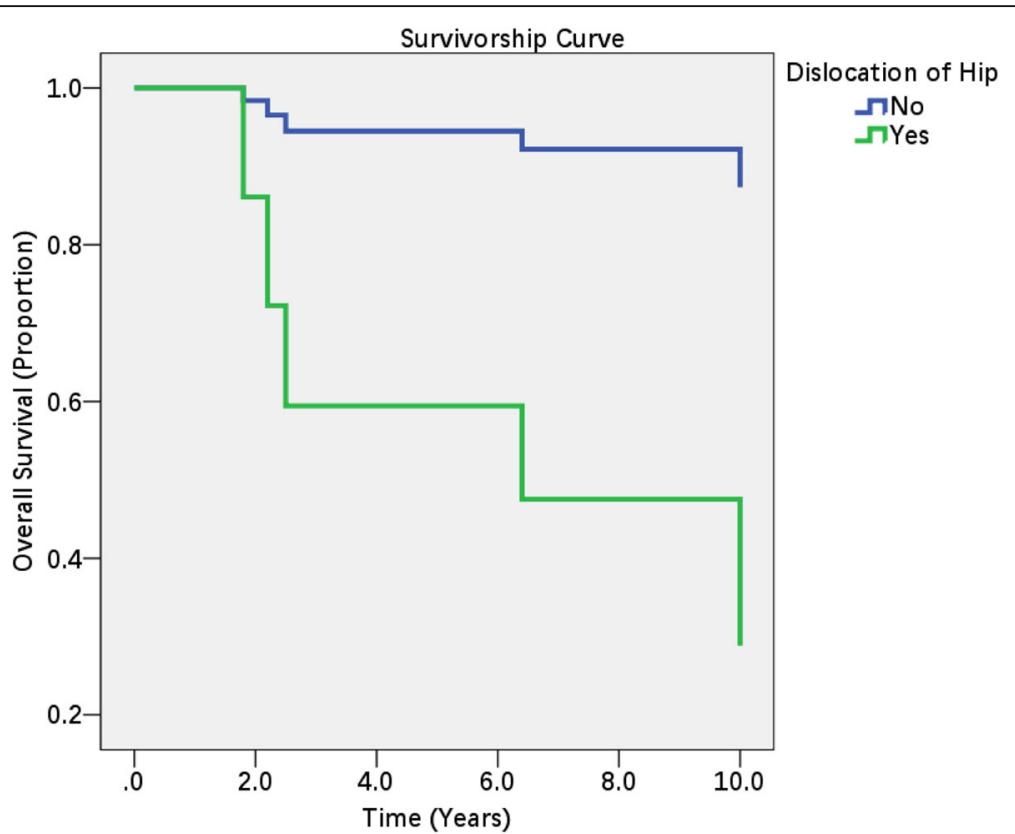

Fig. 1 Survivorship curve for patients with an acetabular fracture and ipsilateral intertrochanteric fracture. Note: One elderly (87 years) female patient was excluded from our study cohort because she had a chronic pulmonary disease and died of pulmonary infection at 24 days postoperatively. Patients were considered have a poor outcome if they had a Harris score less than 80 points or underwent total hip arthroplasty

additional injuries, but we did not account for any additional injuries in the analysis. Third, we found that hip dislocation was an independent risk factor for poor patient outcomes. However, all cases of dislocation of the hip joint were reduced several days after injury; thus, we cannot determine whether early reduction is helpful for reducing the incidence of avascular necrosis and further improving the prognosis of patients.

\section{Conclusions}

To sum up, high-impact trauma is the main cause of acetabular fracture and concomitant ipsilateral intertrochanteric femur fracture. For patients who have undergone surgical treatment, fracture healing is usually achieved. However, the occurrence of complications, especially avascular necrosis, is the major cause of a poor prognosis. Dislocation of the hip joint at the time of

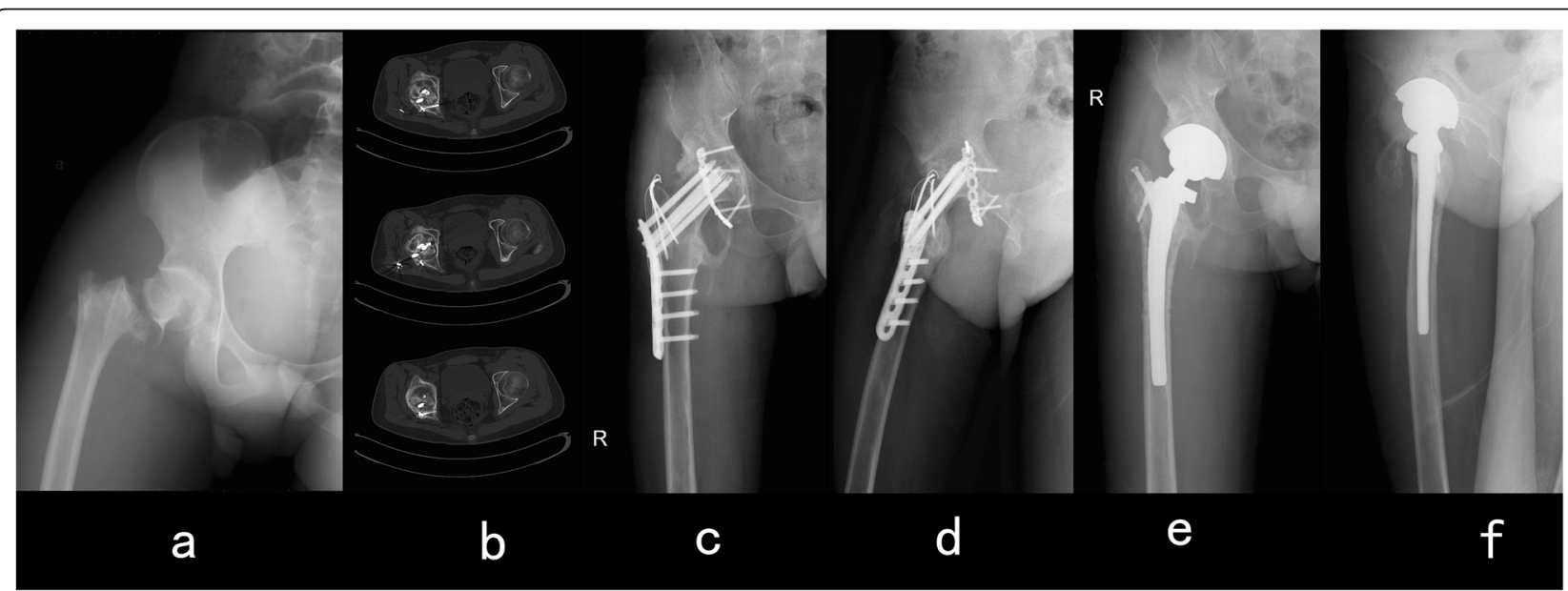

Fig. 2 Case 11. A 22-year-old male patient had a traumatic acetabular fracture combined with an ipsilateral intertrochanteric fracture in his right hip. The patient underwent open reduction and internal fixation surgery for both his acetabulum and proximal femur. Then, 2.2 years after surgery, avascular necrosis of the right femoral head was detected, and revision with total hip arthroplasty was performed. a Anterior-posterior view immediately after injury. b Computed tomography image showing avascular necrosis of the right femoral head. $\mathbf{c}$ Anterior-posterior view before hip arthroplasty. $\mathbf{d}$ Lateral view before hip arthroplasty. e Anterior-posterior view after hip arthroplasty. $\mathbf{f}$ Lateral view after hip arthroplasty 

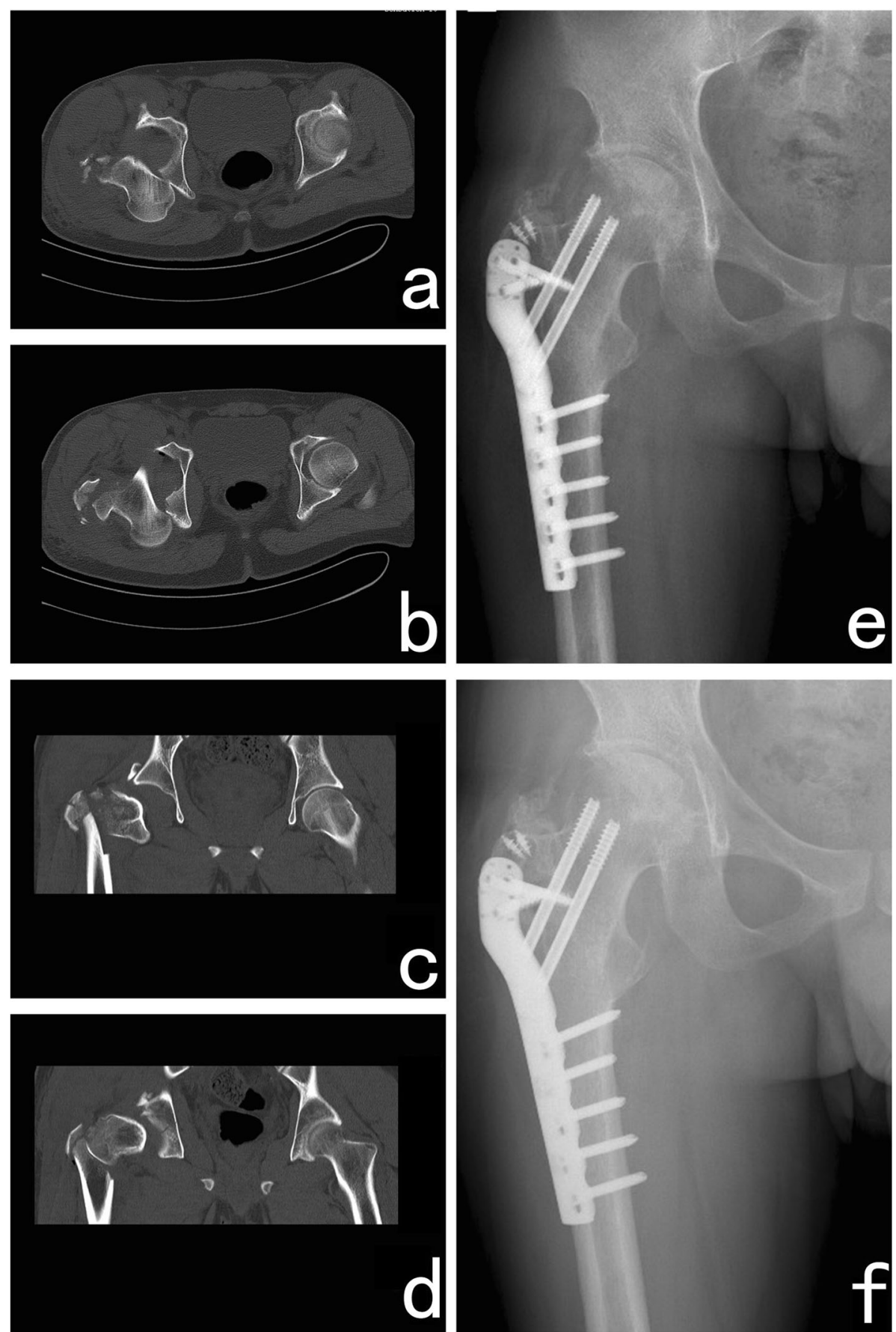

Fig. 3 Case 17. A 28-year-old male patient had a traumatic acetabular fracture combined with an ipsilateral intertrochanteric fracture in his right hip. The patient underwent open reduction and internal fixation surgery for both his acetabulum and proximal femur. An absorbable screw was used to fix the fracture fragment of the posterior wall. Plates and screws were used to fix the intertrochanteric fracture. a-d Computed tomography image showing a posterior wall fracture of the acetabulum and dislocation of the hip joint. e Anterior-posterior view at the final follow-up. $\mathbf{f}$ Lateral view before hip arthroplasty at the final follow-up 
injury is considered to be an important risk factor for a poor prognosis.

\section{Abbreviations}

ORIF: Open reduction and internal fixation; CRIF: Closed reduction and internal fixation; VAS: Visual analogue scale; THA: Total hip arthroplasty; DHS: Dynamic hip screw; HO: Heterotopic ossification; HR: Hazard ratio; Cl: Confidence interval

\section{Acknowledgements}

Not applicable.

\section{Authors' contributions}

All authors have read and approved the manuscript. Conceptualization: Bo Liu, Yongtai Han. Data curation: Bo Liu, Wenhui Ma, Sikai Liu, Huijie Li. Methodology: Bo Liu, Xiao Chen, Wenhui Ma, Mengnan Li, Huijie Li. Writing: Bo Liu, Sikai Liu, Jia Huo, Yongtai Han.

\section{Funding}

The study was funded in part by the Nature Science Foundation of Hebei, China (grant no. H2019206609).

\section{Availability of data and materials}

All data generated or analysed during this study are included in this published article.

\section{Ethics approval and consent to participate}

This study was approved by the Institutional Review Board of the Third Hospital of Hebei Medical University (no. K20190031) and was conducted in accordance with the Declaration of Helsinki. As this was a retrospective study and all patient information was deidentified before analysis, informed consent was only required for the patients whose radiological images were selected for publication.

\section{Consent for publication}

Written informed consent was obtained from the participants whose radiological data were selected for publication in the journal.

\section{Competing interests}

All the authors declare that they have no conflicts of interest with any of the organizations that sponsored the research.

\section{Received: 28 September 2020 Accepted: 30 November 2020} Published online: 09 December 2020

\section{References}

1. Ahmed M, Abuodeh Y, Alhammoud A, Salameh M, Hasan K, Ahmed G. Epidemiology of acetabular fractures in Qatar. Int Orthop. 2018;42(9):2211-7. https://doi.org/10.1007/s00264-018-3824-z.

2. Zyman Corenstein J, Martinez Del Campo Sanchez A. Acetabulum fractures in the Mexican population. Acta Ortop Mex. 2018;32(5):251-6.

3. Pascarella R, Fantasia R, Sangiovanni P, Maresca A, Massetti D, Politano R, et al. Traumatic hip fracture-dislocation: a middle-term follow up study and a proposal of new classification system of hip joint associated injury. Injury. 2019;50(Suppl 4):S11. https://doi.org/10.1016/j.injury.2019.01.011.

4. Kuhn KM, Boudreau JA, Watson JT. Rare combination of ipsilateral acetabular fracture-dislocation and pertrochanteric fracture. Am J Orthop (Belle Mead NJ). 2013:42(8):372-5.

5. Barrett MO, Anglen JO, Hoernschemeyer DG, Schnetzler KA. Case report: associated both-column acetabulum fracture with an ipsilateral centrally dislocated intertrochanteric femur fracture. J Trauma. 2009;66(3):918-21. https://doi.org/10.1097/01.ta.0000224118.24154.39.

6. Browne RS, Mullan GB. Intertrochanteric fracture of the femur with ipsilateral central fracture of the acetabulum. Injury. 1980;11(3):251-3.

7. Mediouni M, D RS, Madry H, Cucchiarini M, Rai B. A review of translational medicine. The future paradigm: how can we connect the orthopedic dots better? Curr Med Res Opin. 2018;34(7):1217-29. https://doi.org/10.1080/ 03007995.2017.1385450.

8. Mediouni M. A new generation of orthopaedic surgeons: "T-model". Cur Orthop Pract. 2019;30:1. https://doi.org/10.1097/BC0.0000000000000786.
9. Mediouni M, Madiouni R, Gardner M, Vaughan N. Translational medicine: challenges and new orthopaedic vision (Mediouni-model). Curr Orthop Pract. 2019;31:1. https://doi.org/10.1097/BCO.0000000000000846.

10. Swiontkowski M, Agel J, McAndrew M, Burgess A, Mackenzie E. Outcome validation of the AO/OTA fracture classification system. J Orthop Trauma. 2000;14:534-41. https://doi.org/10.1097/00005131-200011000-00003.

11. Ziran N, Soles GLS, Matta JM. Outcomes after surgical treatment of acetabular fractures: a review. Patient Saf Surg. 2019;13:16. https://doi.org/ 10.1186/s13037-019-0196-2.

12. Aubrun F, Langeron $\mathrm{O}$, Quesnel $\mathrm{C}$, Coriat $\mathrm{P}$, Riou B. Relationships between measurement of pain using visual analog score and morphine requirements during postoperative intravenous morphine titration. Anesthesiology. 2003; 98(6):1415-21. https://doi.org/10.1097/00000542-200306000-00017.

13. Thomas SH, Andruszkiewicz LM. Ongoing visual analog score display improves emergency department pain care. J Emerg Med. 2004;26(4):38994. https://doi.org/10.1016/j.jemermed.2003.11.020.

14. Matta JM. Fractures of the acetabulum: accuracy of reduction and clinical results in patients managed operatively within three weeks after the injury. J Bone Joint Surg Am. 1996;78(11):1632-45.

15. Alonso JE, Volgas DA, Giordano V, Stannard JP. A review of the treatment of hip dislocations associated with acetabular fractures. Clin Orthop Relat Res. 2000;377:32-43.

16. Chen J, Zhang D, Zhang T, Chen C, Song Y, Liu S, et al. Effect of the vascularized bone components on the survival of vascularized composite allografts. J Surg Res. 2018;224:132-8. https://doi.org/10.1016/j.jss.2017.03.050.

17. Frascone RJ, Salzman JG, Adams AB, Bliss P, Wewerka SS, Dries DJ. Evaluation of intraosseous pressure in a hypovolemic animal model. J Surg Res. 2015;193(1):383-90. https://doi.org/10.1016/j.jss.2014.07.007.

18. Boelch SP, Jordan MC, Meffert RH, Jansen H. Comparison of open reduction and internal fixation and primary total hip replacement for osteoporotic acetabular fractures: a retrospective clinical study. Int Orthop. 2017:41(9): 1831-7. https://doi.org/10.1007/s00264-016-3260-x.

19. Askam B, Sims S. Supplemental superior buttress plating for the treatment of posterosuperior wall acetabulum fractures. J Orthop Trauma. 2019; 33(Suppl 2):S27-s31. https://doi.org/10.1097/bot.0000000000001394.

20. Chen J, Liu H, Wang C, Lin X, Gu C, Fan S. Internal fixation of acetabular fractures in an older population using the lateral-rectus approach: shortterm outcomes of a retrospective study. J Orthop Surg Res. 2019;14(1):4. https://doi.org/10.1186/s13018-018-1039-z.

21. He C, Feng JM, Yang QM, Wang Y, Liu ZH. Results of selective hip arthroplasty revision in isolated acetabular failure. J Surg Res. 2010;164(2): 228-33. https://doi.org/10.1016/j.jss.2009.06.023.

22. Giunta JC, Tronc C, Kerschbaumer G, Milaire M, Ruatti S, Tonetti J, et al. Outcomes of acetabular fractures in the elderly: a five year retrospective study of twenty seven patients with primary total hip replacement. Int Orthop. 2018. https://doi.org/10.1007/s00264-018-4204-4.

23. Hsu CL, Chou YC, Li YT, Chen JE, Hung CC, Wu CC, et al. Pre-operative virtual simulation and three-dimensional printing techniques for the surgical management of acetabular fractures. Int Orthop. 2018;43(8):1969. https://doi. org/10.1007/s00264-018-4111-8.

24. Kashyap S, Mahajan S, Lal M. Effects of topical tranexamic acid during open reduction and internal fixation of acetabular fractures: a retrospective study. Acta Orthop Traumatol Turc. 2019;53(3):175. https://doi.org/10.1016/j.aott.2019.03.006.

25. Noda M, Takahashi M, Nukuto K, Fujita M, Shinohara I, Suda Y, et al. Innovative technique of minimally invasive closed reduction for impacted femoral neck fractures (MICRIF). J Orthop Surg (Hong Kong). 2019;27(1):1. https://doi.org/10.1177/2309499019832418.

26. Garcia-Rey E, Sirianni R, Garcia-Cimbrelo E, Sedel L. Total hip arthroplasty after acetabular fracture: does initial treatment make any difference to the outcome? A 5- to 23-year follow-up with clinical and radiological analysis. Hip Int. 2019;1:1. https://doi.org/10.1177/1120700019836413.

27. Stewart RG, Hammer N, Kieser DC. External fixation of unstable pelvic fractures: a systematic review and meta-analysis. ANZ J Surg. 2019;89(9): 1022. https://doi.org/10.1111/ans.15027.

28. Beebe MJ, Bauer JM, Mir HR. Treatment of hip dislocations and associated injuries: current state of care. Orthop Clin North Am. 2016;47(3):527-49. https://doi.org/10.1016/j.ocl.2016.02.002

\section{Publisher's Note}

Springer Nature remains neutral with regard to jurisdictional claims in published maps and institutional affiliations. 